Research Article

\title{
Effect of Pelvic Floor Muscle Exercises on Severity of Urinary Incontinence among Elderly Female Patients
}

\author{
Bincy Rajan
}

Clinical Instructor, Department of Medical Surgical Nursing, Pragyan College of Nursing Bhopal, Madhya Pradesh, India. DOI: https://doi.org/10.24321/2348.2133.201903

\section{I $\quad \mathbf{N} \quad \mathbf{F} \quad \mathbf{O}$}

\section{E-mail Id:}

bincy1992rajan@gmail.com

Orcid Id:

https://orcid.org/0000-0003-3030-426X

How to cite this article:

Rajan B. Effect of Pelvic Floor Muscle Exercises on Severity of Urinary Incontinence among Elderly Female Patients. Ind J Holist Nurs 2019; 10(1): 16-26.

Date of Submission: 2019-08-31

Date of Acceptance: 2019-10-14

\section{$\begin{array}{llllllll}\mathbf{A} & \mathbf{B} & \mathbf{S} & \mathbf{T} & \mathbf{R} & \mathbf{A} & \mathbf{C} & \mathbf{T}\end{array}$}

Introduction: Prevention of urinary incontinence at primary level is a significant task for all health care workers. Current treatments include many behavioral modalities among which PFME is one of the effective strategies. In the present setting there is lack of practice of PFME as a preventive and curative strategy among elderly females.

Objective: To compare the severity of urinary incontinence before and after pelvic floor muscle exercise, to determine the association of severity of urinary incontinence with selected baseline variables.

Methodology: Quasi experimental one group pre-test post-test research design with purposive sampling technique was used to collect data from 35 elderly females with urinary incontinence in IPD, Senior Citizen OPD and OBG OPD of selected hospital, Bangalore. QUID (Questionnaire for Urinary Incontinence Diagnosis) was used to identify the type of urinary incontinence and ICIQ UI SF (International Consultation on Incontinence Questionnaire-Short Form) was used to assess the severity of urinary incontinence. Data was analysed using both descriptive and inferential statistics on the basis of objectives and hypothesis of the study. Frequency, percentage, mean, standard devation of the data was analysed in terms of descriptive statistics and paired $t$ test, independent t-test and ANOVA test of inferential statistics were used to assess the level of significance.

Result: There was a significant reduction of mean severity score of pre-test from $12.23 \pm 2.03$ to $9.89 \pm 1.8$ at $p$ value $<0.001$. Mean of three content areas of $\mathrm{UI}$ (frequency, amount and impact of urine leakage) reduced from $3.14 \pm 0.69$ to $2.34 \pm 0.68,3.26 \pm 1.09$ to $2.49 \pm 0.85$ and $5.83 \pm 1.01$ to $5.06 \pm 0.93$ at $p$-value $<0.001$. There was no statistically significant association between any of the baseline variables with severity of urinary incontinence.

Conclusion: The health professionals need to focus more on providing training and positive reinforcement to these patients as PFME is one of the most common mode of management for patients with urinary incontinence.

Keywords: PFME, Severity of Urinary Incontinence, ICIQ UI SF, QUID 


\section{Introduction}

Among geriatric population, older women have higher incidence of chronic health problems. Urinary incontinence is the eighth most prevalent chronic medical condition among elderly women. International Continence Society (ICS) has defined urinary incontinence as the involuntary loss of urine which is a social or hygienic problem which can be classified as stress urinary incontinence, urge urinary incontinence and mixed urinary incontinence. ${ }^{1}$ It affects the physical activities, self-perception, self-confidence \& social activities which affects quality of life.

According to WHO one out of every three women worldwide, across all age groups is reported to have urinary incontinence problem. A survey conducted in India revealed that among 3000 older women, $21.8 \%$ women were incontinent out of which nearly $73.8 \%$ were found to have stress urinary incontinence, followed by $16.8 \%$ as mixed urinary incontinence $\& 9.5 \%$ as urge incontinence. ${ }^{1}$ A wide range of treatment options are available in terms of conservative treatment techniques for elderly patients who are incontinent. These treatment techniques may lead to a decrease in complaints of up to $30-50 \%$. Treatment strategies include life style modification, exercises, vaginal devices, medicines and surgical intervention. Behavioral techniques are now currently recommended as first line treatment of urinary incontinence, as they are relatively inexpensive and easy to implement. ${ }^{2}$

The investigator felt that pelvic floor muscle exercises are simple, non-pharmacological, noninvasive, easy to perform and an effective intervention for urinary incontinence. Also, very few Indian studies are done to observe the benefits of pelvic floor muscle exercises on urinary incontinence especially among old age women. Therefore, the investigator felt a strong need to undertake a study to assess the effect of pelvic floor muscle exercises on urinary incontinence among elderly females.

\section{Assumptions}

Urinary incontinence may affect the functional ability of elderly females and pelvic floor muscle exercises may change severity of urinary incontinence among elderly women.

\section{Operational Definitions}

\section{Effect}

In this study it refers to the change in severity of urinary incontinence experienced by elderly female patients after performing pelvic floor muscle exercises as determined by the difference in pre and post-test scores obtained on ICIQ UI SF (International Consultation on Incontinence Questionnaire Urinary Incontinence Short Form).

\section{Elderly Females}

In this study it refers to women between the age group
50 to 80 years from IPD, Senior citizen clinic and OBG OPD at SJMCH.

\section{Pelvic Floor Muscle Exercises}

In this study it refers to exercise designed to strengthen the muscles of pelvic floor, pelvic girdle and the pubococcygeal muscles by contraction of these muscles for 10 seconds followed by 10 seconds relaxation forming one session which will be demonstrated by a video then performed by the subjects 3 times a day for minimum 4 weeks duration.

\section{Urinary Incontinence}

In this study it refers to the involuntary leakage of urine at an inappropriate time \& in an inappropriate place, which can be in the form of stress, urge and mixed type of incontinence among elderly females as determined by the scores obtained on QUID (Questionnaire for Urinary Incontinence Diagnosis).

\section{Baseline Variables}

In this study selected baseline variable refers to patient's age, educational status, parity, mode of child birth, family income, BMI, Practice of Yoga/ exercise and type of urinary incontinence (stress, urge or mixed).

\section{Methodology}

The data was collected from $20^{\text {th }}$ November to $31^{\text {st }}$ March 2017 in Senior Citizen clinic, Obstetrics and Gynecology OPD and in In Patient Department of St. John's Medical College Hospital, Bangalore.

Administrative approval was obtained from SJMCH. (St. John's Medical College Hospital, Bangalaore, Karnataka). Purposive sampling technique was used based on inclusion and exclusion criteria. According to inclusion and exclusion criteria women between the age group of 50-80 years and those with com-plaints of urinary incontinence as identified by the physician were included in the study. Elderly women with medical history likely to affect sphincter control such as CNS disease (Multiple Sclerosis, Cardio Vascular Accident or cute mental illness and dementia), recent urological surgeries for less than 3 months, and history of genito urinary malignancy, current urinary infection, hysterectomy and Diabetes Mellitus as well as elderly females with cognitive impairement were excluded from the study. The purpose of the study was explained to the samples and informed consent was obtained. Interview was conducted to elicit the baseline data and QUID (Questionnaire for Female Urinary Incontinence Diagnosis) questionnaire was administered to identify the type of urinary incontinence.

Pre-test was conducted on 48 patients by administering ICIQ UI SF (International Consultation on Incontinence Questionnaire Urinary Incontinence Short Form) to assess the severity of urinary incontinence. 
Pelvic floor muscle exercises were taught to the subjects with the help of a video, approximately for 10 minutes on a one to one basis \& the subjects were instructed to perform the PFME at home for 3 sessions a day, each session lasting 3-4 minutes consisting of 10 contractions of pelvic floor muscles by holding each contraction for 10 seconds followed by 10 seconds relaxation.

Subjects were given a log book to maintain. Log book was prepared in English, Hindi, Kannada, Tamil and Telugu languages. It contained the instructions and techniques to be followed during exercise duration. It had a track of entire 4 weeks of exercise for which each day was divided into 3 time zones as morning, evening and night. As the subjects were instructed to do exercise 3 times per day. After performing it at each time the clients were suppossed to place a tick mark on the respective column. At last in post-test on the basis of tick marks compliance was calculated. The investigator contacted the subjects twice a week to ensure compliance. Subjects with minimum $90 \%$ compliance were retained in the study for post-test which was administered after 4 weeks.

Post-test was conducted by using ICIQ UI SF. Out of 48,10 subjects reported to have less than $90 \%$ compliance to the exercise and 3 subjects refused to come for follow up. Post-test was conducted only on 35 subjects.

\section{Tool}

The tool for data collection consisted of three sections:

\section{Section I (A)}

Proforma to elicit baseline variables by using structured interview schedule. Baseline variable refers to patient's age, educational status, parity, mode of child birth, family income, BMI, Practice of Yoga/ exercise and type of urinary incontinence (stress, urge or mixed).

\section{Section I (B)}

QUID (Questionnaire for Female Urinary Incontinence Diagnosis) was used to identify the type of urinary incontinence. It consisted of 6 items. Each item scores 0 (none of the time), 1 (rarely), 2 (once in a while), 3 (often), 4 (most of the time) or 5 (all of the time). Responses to items $1,2 \& 3$ are summed for the stress incontinence score which should be ( $\geq 4)$; and responses to items 4,5 \& 6 are summed for urge incontinence score which should be $(\geq 6)$. Responses to both stress \& urge urinary incontinence by QUID (stress score $\geq 4$ \& urge score $\geq 6$ ) contributes to mixed urinary incontinence group.

\section{Section II}

ICIQ UI SF (International Consultation on Incontinence Questionnaire Urinary Incontinence Short Form) was used to assess the severity of urinary incontinence. It comprises of 3 scored items, question no. 3 to assess the frequency of urinary incontinence (score 0-5), question no. 4 to assess the amount of urinary incontinence (score $0-6$ ), and question no. 5 to assess its impact on the individual's quality of life (score 0-10). Question no. 6 is an unscored self-diagnostic item to assess the perceived causes of leakage. The score is obtained by adding the scores from the three scored items together to give a score range between 0 \& 21; the higher the score the greater the severity. Severity scores are divided into different levels such as slight UI ranging from 0-6, moderate UI between 7-11, severe UI between 12-16 and very severe UI between 17-21.

\section{Reliability}

\section{QUID (Questionnaire for Female Urinary Incontinence Diagnosis)}

As the tools were standardised, reliability was not checked by the investigator but according to author's information, the test re test reliability of QUID (Questionnaire for Female Urinary Incontinence Diagnosis) was very good with 95\% confidence interval and high kappa value of 0.91 and $\alpha$ co-efficient of internal consistency was .87.

\section{ICIQUI (International Consultation on Incontinence Questionnaire Urinary Incontinence)}

According to author's information the test re test reliability of ICIQ (International Consultation on Incontinence Questionnaire Urinary Incontinence) was also good with $92 \%$ confidence interval of high kappa value of 0.74 and $\alpha$ co-efficient was very high as 0.95 indicating excellent internal consistency.

\section{Validity}

As the tools were standardised, the appropraiteness of the tool in Indian setting was established through content validity by 8 experts who were Obstetricians and Medical Surgical nursing experts thus corrections were included.

\section{Result}

The data collected were tabulated, analyzed and interpreted, using descriptive and inferential statistics, which were necessary to provide substantive summary of results. The analyzed data has been organized and presented in the following sections.

\section{Section I}

Description of baseline variables of patients with urinary incontinence.

\section{Section 2}

Comparison of pre-test and post-test severity scores of patients with urinary incontinence.

\section{Section 3}

Association of severity scores with selected baseline variables. 
Section I

Table I(a).Frequency and percentage distribution of elderly females with urinary incontinence according to age, parity, BMI and income

\begin{tabular}{|c|c|c|c|c|c|}
\hline S. No. & Baseline Variables & Frequency (f) & Percentag (\%) & Mean/ Median & SD \\
\hline 1. & Age (yrs.) & & & & \\
\hline & $50-59$ & 7 & 25.7 & \multirow{3}{*}{64.63} & \multirow{3}{*}{8.06} \\
\hline & $60-69$ & 19 & 54.3 & & \\
\hline & $70-79$ & 9 & 20 & & \\
\hline \multirow[t]{3}{*}{2.} & Parity & & & & \\
\hline & $\leq 2$ & 12 & 34.3 & \multirow{2}{*}{$3^{M}$} & \multirow{2}{*}{2.09} \\
\hline & $>2$ & 23 & 65.7 & & \\
\hline \multirow[t]{5}{*}{3.} & BMI & & & & \\
\hline & $<18.5$ (underweight) & 2 & 5.7 & \multirow{4}{*}{25.01} & \multirow{4}{*}{4.17} \\
\hline & 18.5-24.9 (normal weight) & 19 & 54.3 & & \\
\hline & 25.0-29.9 (over weight) & 9 & 25.7 & & \\
\hline & 30.0-34.9 (obese) & 5 & 14.3 & & \\
\hline \multirow[t]{3}{*}{4.} & Income & & & & \\
\hline & $\leq 15,000$ & 15 & 42.9 & \multirow{2}{*}{$21171.7^{\mathrm{M}}$} & \multirow{2}{*}{8939.2} \\
\hline & $>15,000$ & 20 & 57.1 & & \\
\hline
\end{tabular}

Table 1(a), depicts that in the present study $54.3 \%$ of the elderly females were between the age group of 60-69 and $65.7 \%$ of them had parity of more than $2.54 .3 \%$ of the elderly females had normal BMI. $57.1 \%$ of them had monthly income $>15,000$.

Table I(b). Frequency and percentage distribution of elderly females with urinary incontinence according

to education, occupation and mode of delivery

\begin{tabular}{|c|c|c|c|}
\hline $\begin{array}{c}\text { S. } \\
\text { No. }\end{array}$ & Baseline Variables & $\begin{array}{c}\text { Frequency } \\
\text { (f) }\end{array}$ & $\begin{array}{c}\text { Percentage } \\
\text { (\%) }\end{array}$ \\
\hline 1. & Education & & \\
\hline & Illiterate & 14 & 40 \\
\hline & $\begin{array}{c}\text { Primary/ middle/ } \\
\text { High/Intermediate }\end{array}$ & 11 & 31.4 \\
\hline & Graduate & 10 & 28.6 \\
\hline 2. & Occupation & & \\
\hline & Employed & 13 & 37.1 \\
\hline & Unemployed & 22 & 62.9 \\
\hline 3. & Mode of Delivery & & \\
\hline & NL & 33 & 94.3 \\
\hline & LSCS & 1 & 2.9 \\
\hline & Instrumental & 1 & 2.9 \\
\hline
\end{tabular}

Table 1(b), depicts in the present study that $40 \%$ of the elderly females were illiterate. $62.9 \%$ of them were unemployed and $94.3 \%$ had delivered through normal labor.

Table I(c).Frequency and percentage distribution of elderly females with urinary incontinence according to practice of yoga/ exercise and type of urinary incontinence

\begin{tabular}{|c|c|c|c|}
\hline $\begin{array}{c}\text { S. } \\
\text { No. }\end{array}$ & Baseline Variables & $\begin{array}{c}\text { Frequency } \\
\text { (f) }\end{array}$ & $\begin{array}{c}\text { Percentage } \\
\text { (\%) }\end{array}$ \\
\hline 1. & $\begin{array}{c}\text { Practice of Yoga/ } \\
\text { Exercise }\end{array}$ & & \\
\hline & Yes & 2 & 5.7 \\
\hline & No & 33 & 94.3 \\
\hline 2. & $\begin{array}{c}\text { Type of Urinary } \\
\text { Incontinence }\end{array}$ & 20 & 57.1 \\
\hline & $\begin{array}{c}\text { Stress urinary } \\
\text { incontinence }\end{array}$ & 22.9 \\
\hline & $\begin{array}{c}\text { Urge urinary } \\
\text { incontinence }\end{array}$ & 8 & 20.0 \\
\hline & $\begin{array}{c}\text { Mixed urinary } \\
\text { incontinence }\end{array}$ & 7 & \\
\hline
\end{tabular}

Table 1(c), depicts in the present study that $94.3 \%$ of the elderly females didn't practice any yoga or exercise to resolve the problem and $57.1 \%$ of them had stress urinary incontinence. 


\section{Section 2}

Comparison of pretest and post test scores of patients with urinary incontinence

\section{Objective}

To compare the severity of urinary incontinence before and after pelvic floor muscle exercises

\section{Hypothesis}

$\mathbf{H}_{\mathbf{1}}$ : There will be a significant difference in the severity of urinary incontinence experienced by the elderly female patients before and after pelvic floor muscle exercises at 0.05 level of significance.

Data presented in Table 2(a), shows that there is significant decrease in the mean severity scores of urinary incontinence after video assisted teaching of PFME. The mean pretest scores of urinary incontinence is $12.23 \pm 2.03$ and mean post test scores of urinary incontinence is $9.89 \pm 1.8$ with a mean difference of 2.34. The obtained t value is 8.7 , which is significant at $p<0.05$ level. ( $p$-value $<0.001$ ). Thus hypothesis no. 1 is accepted.

From the figure 1, it is evident that in pre-test $3 \%$ of patients had very severe urinary incontinence which reduced to $0 \%$ in post test, $57 \%$ of patients had severe urinary incontinence before the intervention which reduced to $9 \%$ in post test. $40 \%$ of patients were in the category of moderate $\mathrm{UI}$ in pre-test while in post-test most of the patients (91\%) were in moderate category.

Figure 2, shows that there has been a decrease in UI in all 3 content areas (namely frequency, amount and impact of urine leakage) in the post test. Mean score of frequency of urine leakage decreased from 3.14 to 2.34, mean score of amount of urine leakage decreased from 3.26 to 2.49 and mean score of impact of urine leakage decreased from 5.83 to 5.06 .

Table 2(a).Mean, standard deviation and paired't' test to compare the pre-test and post test scores of patients with urinary incontinence

\begin{tabular}{|c|c|c|c|c|c|c|c|c|}
\hline S. No. & Items & Maximum Score & Range & Mean & SD & Mean Difference & Paired t-test & p-value \\
\hline 1. & Pre-test & 21 & $9-18$ & 12.23 & 2.03 & \multirow{2}{*}{2.34} & \multirow{2}{*}{8.7} & $<0.001 *$ \\
\hline 2. & Post-test & & $7-16$ & 9.89 & 1.8 & 2.3 & & \\
\hline
\end{tabular}

*Significant

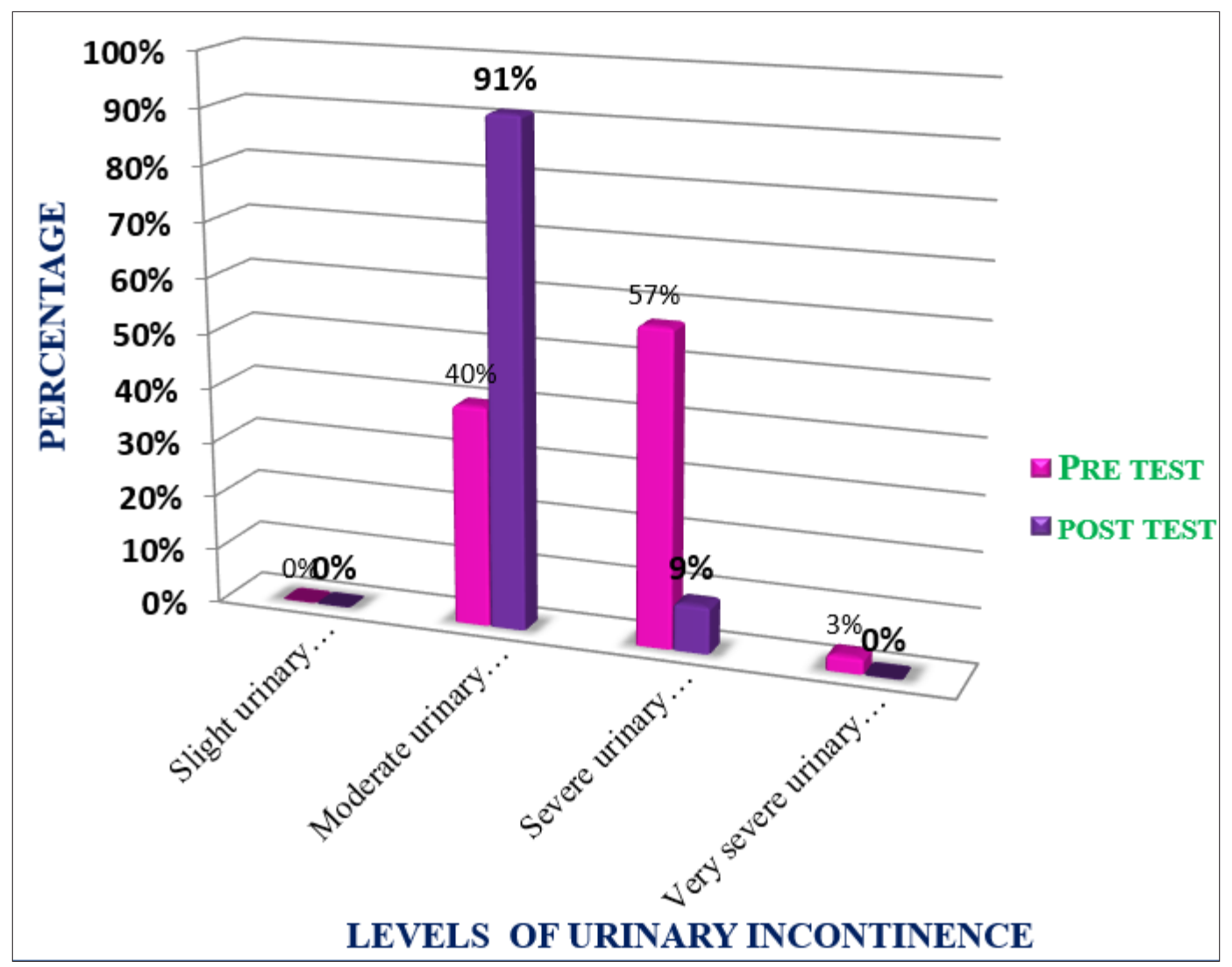

Figure I.Comparison of levels of UI in Pre Test and Post Test 


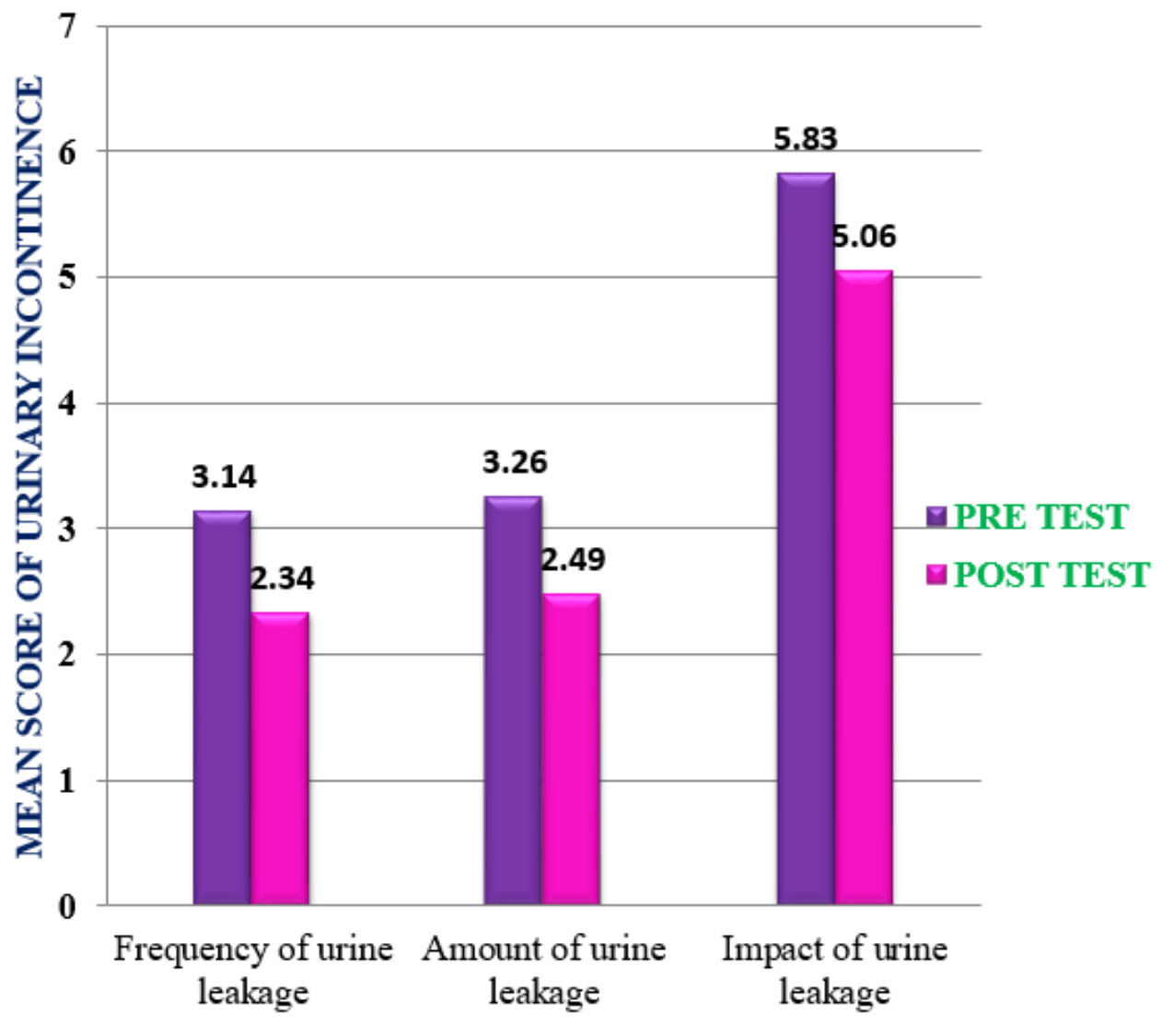

CONTENT AREAS OF URINARY INCONTINENCE

Figure 2.Comparison of Pre Test and Post Test mean scores of Frequency, Amount and Impact of UI

Table 2(b).Mean, SD \& paired ' $t$ ' test to compare the pretest and post test scores of content areas namely frequency, amount $\&$ impact of urine leakage

\begin{tabular}{|c|c|c|c|c|c|c|}
\hline S. No. & Content & Mean & SD & Mean Difference & Paired t-test & p-value \\
\hline \multirow[t]{3}{*}{1.} & Frequency of leakage & & & & & \\
\hline & Pre-test & 3.14 & 0.69 & \multirow{2}{*}{0.80} & \multirow{2}{*}{8.90} & \multirow{2}{*}{$<0.001^{*}$} \\
\hline & Post-test & 2.34 & 0.68 & & & \\
\hline \multirow[t]{3}{*}{2.} & Amount of leakage & & & & & \\
\hline & Pre-test & 3.26 & 1.09 & \multirow{2}{*}{0.77} & \multirow{2}{*}{4.42} & \multirow{2}{*}{$<0.001^{*}$} \\
\hline & Post-test & 2.49 & 0.85 & & & \\
\hline \multirow[t]{3}{*}{3.} & Impact of leakage & & & & & \\
\hline & Pre-test & 5.83 & 1.01 & \multirow{2}{*}{0.77} & \multirow{2}{*}{5.92} & \multirow{2}{*}{$<0.001^{*}$} \\
\hline & Post-test & 5.06 & 0.93 & & & \\
\hline
\end{tabular}

*Significant

Data presented in Table 2(b), shows that mean of pre test scores of frequency of urine leakage is $3.14 \pm 0.69$ and mean of post test scores is $2.34 \pm 0.68$, there is statistical significant difference as the $p$-value is $<0.001$. Mean of pre test scores of amount of urine leakage is $3.26 \pm 1.09$ and mean of post test scores is $2.49 \pm 0.85$, there is statistical significant difference as the $p$-value is $<0.001$. Mean of pre test scores of impact of urine leakage is $5.83 \pm 1.01$ and mean of post test scores is $5.06 \pm 0.93$, there is statistical significant difference as the $p$-value is $<0.001$. Thus there is a statistical significant difference between pre and post test scores in all 3 content areas of UI namely frequency, 
amount \& impact of urine leakage.

\section{Section 3}

Association of Severity Of Ui With Selected Baseline Variables

\section{Objective}

To determine the association of severity of urinary incontinence with selected baseline variables.

\section{Hypothesis}

$\mathbf{H}_{2}$ : There will be a significant association between severity of urinary incontinence and selected baseline variables at $0.05 \%$ level of significance.
The table 3(a), depicts in the present study that there is no significant association of severity of urinary incontinence with age, parity, BMI and income of elderly females with urinary incontinence and thus hypothesis no. 2 is rejected.

The table 3(b), depicts in the present study that there is no significant association of severity of urinary incontinence with education, occupation and mode of delivery of elderly females with urinary incontinence and thus hypothesis no. 2 is rejected.

The table 3(c), depicts in the present study that there is no significant association of severity of urinary incontinence with practice of yoga or exercise and type of urinary incontinence, thus hypothesis no. 2 is rejected.

Table 3(a).Frequency, percentage and test of significance to determine the association of severity scores with age, parity, BMI and income

\begin{tabular}{|c|c|c|c|c|c|c|}
\hline S. No. & Baseline Variables & Frequency (f) & Mean & SD & f-Test / t-Test & p-value \\
\hline 1. & Age (yrs.) & & & & & \\
\hline & $50-59$ & 7 & 12.6 & 2.9 & \multirow{3}{*}{$0.25^{A}$} & \multirow{3}{*}{$\begin{array}{l}0.77 \\
\text { NS }\end{array}$} \\
\hline & $60-69$ & 19 & 12.0 & 1.8 & & \\
\hline & $70-79$ & 9 & 12.4 & 1.5 & & \\
\hline \multirow[t]{3}{*}{2.} & Parity & & & & & \\
\hline & $\leq 2$ & 12 & 12.2 & 2.1 & \multirow{2}{*}{0.04} & 0.9 \\
\hline & $>2$ & 23 & 12.2 & 1.9 & & NS \\
\hline \multirow[t]{5}{*}{3.} & BMI & & & & & \\
\hline & $<18.5$ & 2 & 10.5 & 2.1 & \multirow{4}{*}{$1.45^{\mathrm{A}}$} & \multirow{4}{*}{$\begin{array}{l}0.2 \\
\text { NS }\end{array}$} \\
\hline & $18.5-24.9$ & 19 & 11.9 & 1.8 & & \\
\hline & $25.0-29.9$ & 9 & 12.4 & 2.3 & & \\
\hline & $30.0-34.9$ & 5 & 13.6 & 1.8 & & \\
\hline \multirow[t]{3}{*}{4.} & Income & & & & & \\
\hline & $\leq 15,000$ & 15 & 12.3 & 1.5 & \multirow{2}{*}{0.09} & \multirow{2}{*}{$\begin{array}{l}0.9 \\
\text { NS }\end{array}$} \\
\hline & $>15,000$ & 20. & 12.2 & 2.3 & & \\
\hline
\end{tabular}

A=ANOVA, NS=Non Significant

Table 3(b).Frequency, percentage and test of significance to determine the association of severity scores with education, occupation and mode of delivery

$\mathrm{n}=35$

\begin{tabular}{|c|c|c|c|c|c|c|}
\hline S. No. & Baseline Variables & Frequency (f) & Mean & SD & f-Test/ t-Test & p-value \\
\hline 1. & Education & & & & & \\
\hline & Illiterate & 14 & 11.5 & 1.4 & \multirow{3}{*}{$1.55^{\mathrm{A}}$} & \multirow{3}{*}{$\begin{array}{c}0.22 \\
\text { NS }\end{array}$} \\
\hline & Primary/ Middle/ High/ Intermediate & 11 & 12.7 & 2.0 & & \\
\hline & Graduate & 10 & 12.7 & 2.5 & & \\
\hline \multirow[t]{3}{*}{2.} & Occupation & & & & & \\
\hline & Employed & 13 & 12.7 & 2.6 & \multirow{2}{*}{1.06} & 0.3 \\
\hline & Unemployed & 22 & 11.9 & 1.5 & & NS \\
\hline
\end{tabular}




\begin{tabular}{|c|c|c|c|c|c|c|}
\hline 3. & Mode of Delivery & & & & & \\
\hline & $\mathrm{NL}$ & 33 & 12.09 & 1.8 & & \multirow{2}{*}{-} \\
\cline { 1 - 5 } & LSCS & 1 & 11.0 & - & - \\
\hline
\end{tabular}

A=ANOVA, NS=Non Significant

Table 3(c).Frequency, percentage and test of significance to determine the association of severity scores with practice of yoga or exercise and type of urinary incontinence

\begin{tabular}{|c|c|c|c|c|c|c|}
\hline S. No. & Baseline Variables & Frequency (f) & Mean & SD & f-Test/ t-Test & p-value \\
\hline 1. & Practice of Yoga/ Exercise & & & & & \\
\hline & Yes & 2 & 13.5 & 3.5 & \multirow{2}{*}{0.91} & \multirow{2}{*}{$\begin{array}{l}0.3 \\
\text { NS }\end{array}$} \\
\hline & No & 33 & 12.1 & 1.9 & & \\
\hline & Type of Urinary Incontinence & & & & & \\
\hline & Stress urinary incontinence & 20 & 11.6 & 1.7 & \multirow{3}{*}{$2.64^{\mathrm{A}}$} & \multirow{3}{*}{$\begin{array}{c}0.08 \\
\text { NS }\end{array}$} \\
\hline & Urge urinary incontinence & 8 & 12.5 & 2.3 & & \\
\hline 2. & Mixed urinary incontinence & 7 & 13.5 & 1.8 & & \\
\hline
\end{tabular}

A=ANOVA, NS=Non Significant

\section{Discussion}

In the present study, a total of 35 patients were selected. In the current study mean age of subjects was 64.63 with $54.3 \%$ of the subjects in the age group of $60-70,25.7 \%$ in the age group of $70-80$ and $20 \%$ in the age group of $50-60$. A similar study done in India has shown that majority of females $42.8 \%$ who had urinary incontinence were in the age group of $61-70$ with a mean age of $69 .{ }^{1}$ In the current study $40 \%$ of the subjects were illiterate which was supported by a similar study conducted in Hong Kong in which $43.6 \%$ of the subjects were illiterate. ${ }^{3}$ In the present study most of the subjects were unemployed or housewives (62.9\%). Similar findings were seen in a study done in Malaysia where 83.4\% of the incontinent subjects were unemployed. ${ }^{4}$ Majority of the subjects $57.1 \%$ had a monthly income $>15,000$ and $42.9 \%$ had $\leq 15000$. Most of the subjects $65.7 \%$ had parity score above 2 and $34.3 \%$ had either 2 or below 2 which can be supported by a similar study done in Buraidah where majority of the subjects $(66.67 \%)$ had five or more vaginal births because process of delivery causes excessive stretching and pulling of the pelvic floor muscles which in turn makes it weak. ${ }^{5}$ Majority of the subjects $94.3 \%$ delivered through normal labour followed by $2.9 \%$ subjects by LSCS and $2.9 \%$ by forceps delivery, a study conducted in China showed women with a history of vaginal delivery with episiotomy (35.3\%) developed urinary incontinence, $29.9 \%$ had undergone vaginal delivery without episiotomy, 20.8\% had caesarean section and $14 \%$ were nulliparous because Caesarean delivery, particularly pre-labour caesarean, is believed to offer substantial protection against such pelvic floor trauma; in contrast, assisted vaginal delivery, with vacuum or forceps, is believed to carry increased risks of trauma. ${ }^{6}$ Most of the subjects $94.3 \%$ didn't follow any exercise or yoga as a daily routine. Regarding BMI of the subjects $54.3 \%$ of the subjects had normal BMI with mean BMI score as 25.01, a study conducted in India revealed the prevalence of urinary incontinence was $20.77 \%$ and $26.25 \%$ in women with body mass index less than or equal to 25 and more than $25 .{ }^{7}$ Majority of the subjects $57.1 \%$ had stress urinary incontinence followed by $22.9 \%$ as urge incontinence and $20 \%$ as mixed urinary incontinence. A similar study conducted in India showed $57 \%$ women had stress incontinence, $23 \%$ had urge and $20 \%$ had mixed type. ${ }^{8}$

Mean severity scores of urinary incontinence reduced from $12.23 \pm 2.03$ to $9.89 \pm 0.8$ at statistically significant $(p<0.001)$ value. Mean score of three content areas like frequency, amount and impact of urine leakage in pre-test decreased from 3.14 to $2.34,3.26$ to 2.49 and 5.83 to 5.06 in post-test at statistically significant value of $p<0.001$. A similar study conducted in Iran showed the mean score reduction from 10.7 to 9 at $p$ value $<0.001$ and there was a significant difference in all the three components $(p<0.001$ for frequency of urine leakage and amount of leakage and $p<0.01$ for impact of urine leakage). ${ }^{2}$ Comparison of number of subjects in each category between pre-test and post-test showed that while $3 \%$ of the subjects had very severe $\mathrm{UI}$ before intervention, none of the subjects in post-test showed very severe UI. The subjects with severe $\mathrm{Ul}$ reduced from $57 \%$ to $9 \%$ after the intervention. $40 \%$ of the subjects had moderate $\mathrm{UI}$ in pre-test which increased to $91 \%$ in post-test which is a positive finding as subjects with very severe and severe UI moved to the moderate category of UI.

The current study revealed that no statistically significant 
association exists between any of the baseline variables with severity scores of urinary incontinence. Non-significant association of some of the baseline variables with urinary incontinence like income, BMI and socio economic status can be supported by the findings of one of the study conducted in Karim Nagar in India where there was no significant association between the socio-economic, marital status, and body mass index of the respondents and the outcome of urinary incontinence. Discussion of present study with other relevant studies reveals that pelvic floor muscle exercises is an effective technique to reduce the problem of urinary incontinence

\section{Limitations of the Study}

A true experimental study would have given more reliable results. The sample was limited and uniformity of the setting of the study was not maintained as it was conducted both in OPD and IPD. Compliance was assessed using reported practice only. Patients received only one-time exposure to the teaching given by the researcher. Intervention time was limited to one month which can be increased to yield better results.

\section{Implications for Nursing}

Nurses can use pelvic floor muscle exercises as a part of nursing care while managing the elderly females with urinary incontinence and as a preventive measure by elderly multiparous women. Geriatric nurse can be trained to assess urinary incontinence and to teach the exercise to elderly females and family members with the help of video being developed.

Nurse educator can teach the benefits and correct technique of performing pelvic floor muscle exercises to nursing students with the help of video and regular CNE can be conducted.

Nurse administrator can develop protocols in Geriatric OPD and IPD on role of pelvic floor muscle exercises and video can be handed over to those who need.

Researches can be conducted to assess the knowledge of elderly females about role of pelvic floor muscle exercises, to assess the effect of other behavioural modalities on urinary incontinence and regular audits on use of video cane be conducted.

\section{Conclusion}

Since urinary incontinence is one of the common medical problem being experienced by elderly females and pelvic floor muscle exercises is an effective mode of management, these study findings emphasize the need to inculcate the practice of pelvic floor muscle exercises among elderly females as a preventive and curative strategy.

The process of the study was a benefiting and enriching experience to the researcher. It was helpful to prove the positive impact of pelvic floor muscle exercises on urinary incontinence.

\section{Acknowledgement}

I sincerely thank my guide Mrs. Reena Menon, Professor Dept. of Medical Surgical Nursing, St. John's College of Nursing and my co-guide Dr. Shirley George, Professor OBG Dept., St. John's Medical College Hospital, Bangalore for their valuable guidance and suggestions. I thank my head of institution, all the faculty and patients for cooperation.

\section{Conflict of Interest: None \\ References}

1. Singh U, Agrawal P, Verma M. Prevalence \& risk factors of UI in Indian Women: A hospital-based survey. Indian Journal of Urology 2013; 29(1): 31-36. Available from: http://www.indianjurol.com/article.asp?issn=09701591; year=2013; volume=29; issue=1; spage=31; epage =36; aulast=Singh [Google Scholar].

2. Jahromi KM, Talebizadeh M, Mirzaei M. The Effect of Pelvic Muscle Exercises on Urinary Incontinency and Self-Esteem of Elderly Females With Stress Urinary Incontinency, 2013. Global Journal of Health Science 2015; 7: 71-79. [PubMed/ Google Scholar].

3. Leong BS, Mok NW. Effectiveness of a new Standardized Urinary Continence Physiotherapy Programme for Community Dwelling Older Women in Hong Kong. Hong Kong Medical Journal 2015; 21(1): 30-39. [PubMed/ Google Scholar].

4. Mohdsidik S. The Prevalence of Urinary Incontinence among the Elderly in a Rural Community in Selangor. The Malaysian Journal of Medical Sciences 2010; 17(2): 18-23. [PubMed/ Google Scholar].

5. Rikka M, Rufus C, Johnson F et al. Long-term Impact of Mode of Delivery on Stress Urinary Incontinence and Urgency Urinary Incontinence: A Systematic Review and Meta-analysis. European Journal of Urology 2016; 70: 148-158. [PubMed/ Google Scholar].

6. Boliu L, Huaga S, Denglong W. Prevalence \& Risk Factors of Ul among Chinese women in Shanghai. International Journal of Clinical \& Experimental Medicine 2014; 7(3): 686-696. [PubMed/ Google Scholar].

7. Joshi A, Gopalkrishnan S. Effectiveness of pelvic floor muscle exercise on UI among rural perimenopausal women. International Journal of Health Sciences \& Research 2016; 6(1): 315-324.

8. Kerry A, Donovan J, Peters TJ et al. ICIQ: A brief and robust measure for evaluating the symptoms and impact of urinary incontinence. Neurology and Urodynamics 2004; 23: 322-330. 


\section{Appendix of Tools}

\section{ANNEXURE - 11 \\ QUID (Questionnaire for Female Urinary Incontinence Diagnosis)}

INSRUCTIONS-(Please fill up in correct box by providing a tick according to your opinion against each statement)

\begin{tabular}{|c|c|c|c|c|c|c|}
\hline & \multicolumn{6}{|c|}{ SCORING } \\
\hline QUESTIONS & $\begin{array}{l}\text { NONE OF } \\
\text { THE TIME: } \\
\text { SCORE } 0\end{array}$ & $\begin{array}{l}\text { RARELY: } \\
\text { SCORE } 1\end{array}$ & $\begin{array}{l}\text { ONCE IN A } \\
\text { WHILE } \\
\text { SCORE } 2\end{array}$ & $\begin{array}{l}\text { OFTEN: } \\
\text { SCORE } 3\end{array}$ & $\begin{array}{l}\text { MOST OF } \\
\text { THE TIME: } \\
\text { SCORE } 4\end{array}$ & $\begin{array}{l}\text { ALL OF THE } \\
\text { TIME: } \\
\text { SCORE } 5\end{array}$ \\
\hline $\begin{array}{l}\text { Do you leak urine } \\
\text { (even small } \\
\text { drops), wet } \\
\text { yourself, or wet } \\
\text { your pads or } \\
\text { undergarments }\end{array}$ & & & & & & \\
\hline $\begin{array}{l}\text { 1. When you } \\
\text { cough or sneeze? }\end{array}$ & & $\square$ & $\square$ & $\square$ & $\square$ & $\square$ \\
\hline $\begin{array}{l}\text { 2. When you } \\
\text { bend down or lift } \\
\text { something up? }\end{array}$ & & & & & $\square$ & 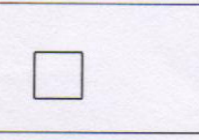 \\
\hline $\begin{array}{l}\text { 3. When you walk } \\
\text { quickly, jog, or } \\
\text { exercise? }\end{array}$ & & & & & & 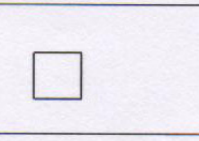 \\
\hline $\begin{array}{l}\text { 4. While you are } \\
\text { undressing in } \\
\text { order to use the } \\
\text { toilet? }\end{array}$ & & & & & & \\
\hline $\begin{array}{l}\text { 5. Do you get } \\
\text { such a strong and } \\
\text { uncomfortable } \\
\text { need to urinate } \\
\text { that you leak } \\
\text { urine (even small } \\
\text { drops) or wet } \\
\text { yourself before } \\
\text { reaching the } \\
\text { toilet? }\end{array}$ & & & & & & \\
\hline $\begin{array}{l}\text { 6. Do you have to } \\
\text { rush to the } \\
\text { bathroom } \\
\text { because you get a } \\
\text { sudden strong } \\
\text { need to urinate? }\end{array}$ & & & 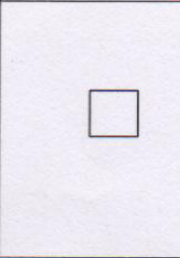 & 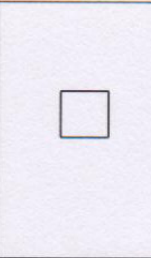 & 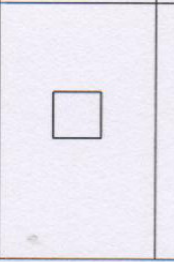 & 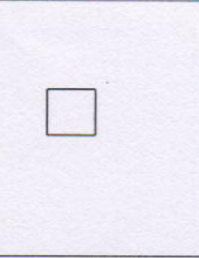 \\
\hline
\end{tabular}




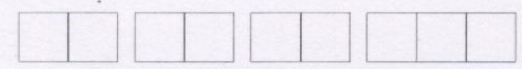

Initial number
ICIQ-UI Short Form

CONFIDENTIAL

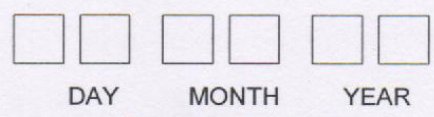

Today's date

Many people leak urine some of the time. We are trying to find out how many people leak urine, and how much this bothers them. We would be grateful if you could answer the following questions, thinking about how you have been, on average, over the PAST FOUR WEEKS

1 Please write in your date of birth:

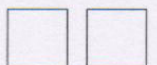

DAY

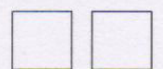

MONTH

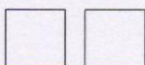

YEAR

Female

Male

2 Are you (tick one):

3 How often do you leak urine? (Tick one box)

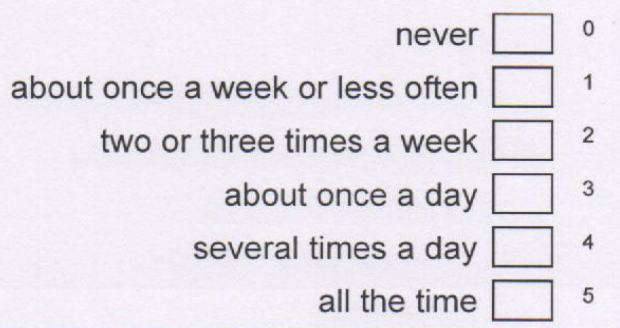

4 We would like to know how much urine you think leaks.

How much urine do you usually leak (whether you wear protection or not)? (Tick one box)

$\begin{array}{rr}\text { none } \square & 0 \\ \text { a small amount } \square & 2 \\ \text { a moderate amount } \square & 4 \\ \text { a large amount } \square & 6\end{array}$

5 Overall, how much does leaking urine interfere with your everyday life? Please ring a number between 0 (not at all) and 10 (a great deal)

$\begin{array}{ccccccccccc}0 & 1 & 2 & 3 & 4 & 5 & 6 & 7 & 8 & 9 & \begin{array}{l}10 \\ \text { not at all }\end{array}\end{array}$

ICIQ score: sum scores $3+4+5$

6 When does urine leak? (Please tick all that apply to you)

never - urine does not leak leaks before you can get to the toilet

leaks when you cough or sneeze leaks when you are asleep leaks when you are physically active/exercising leaks when you have finished urinating and are dressed leaks for no obvious reason leaks all the time

Thank you very much for answering these questions.

Copyright (C) "ICIQ Group" . 